Research Article

\title{
Maternal Characteristics Are Associated with Child Dietary Diversity Score, in Golina District, Northeast Ethiopia: A Community-Based Cross-Sectional Study
}

\author{
Getahun Fentaw Mulaw $\left(\mathbb{D},{ }^{1}\right.$ Fentaw Wassie Feleke $\mathbb{D}^{2},{ }^{2}$ and Seteamlak Adane Masresha ${ }^{2}$ \\ ${ }^{1}$ Public Health Department, College of Health Sciences, Samara University, Samara, Afar, Ethiopia \\ ${ }^{2}$ Public Health Department, College of Health Sciences, Woldia University, Woldia, Ethiopia \\ Correspondence should be addressed to Getahun Fentaw Mulaw; gechfentaw1014@gmail.com
}

Received 13 March 2020; Revised 12 August 2020; Accepted 13 September 2020; Published 22 September 2020

Academic Editor: Jos Mar a Huerta

Copyright (C) 2020 Getahun Fentaw Mulaw et al. This is an open access article distributed under the Creative Commons Attribution License, which permits unrestricted use, distribution, and reproduction in any medium, provided the original work is properly cited.

\begin{abstract}
Background. Dietary diversity is part of the set of indicators developed to assess infant and young child feeding practices. In developing countries, only a quarter of children met the required minimum dietary diversity. In Ethiopia, only $14 \%$ of children aged 6-23 months met the minimum dietary diversity score, with regional variation. Therefore, this study aimed to assess dietary diversity score and associated factors among children aged 6-23 months in Golina district, Afar region, Ethiopia. Method. A community-based cross-sectional study was conducted among 345 study participants from February 15 to March 30, 2017, in Golina district, Afar, Northeast Ethiopia. The study kebeles were selected randomly and the study subjects were selected using a cluster sampling technique. The child dietary diversity score was determined by the WHO child dietary diversity score scale, using a 24-hour dietary recall method, and data were collected using an interviewer-administered questionnaire. Multivariable logistic regression was used to identify predictor variables, and the level of significance was determined at $P$ value $<0.05$. Result. This study revealed that children who met the required minimum dietary diversity score were $35.1 \%$ (95\% CI, (30\%-40\%)). Children whose mothers have not attended formal education were 3.042 times (AOR=3.042 95\% CI: (1.312-7.052)) less likely to meet the minimum dietary diversity score than children whose mothers have attended secondary and above. Children whose mothers had normal BMI were 51.2\% (AOR $=0.488,95 \% \mathrm{CI}:(0.259-918))$ and $68.1 \%(\mathrm{AOR}=0.319,95 \% \mathrm{CI}:(0.119-0.855))$ more likely to meet the minimum dietary diversity score than children whose mothers' BMI was underweight and overweight, respectively. Conclusion. Maternal characteristics (educational status and nutrition status) were found to be associated with their child's dietary diversity score. This study also revealed that children who met the minimum dietary diversity score were few. Therefore, the increased emphasis on the importance of the education of girls (future mothers) and nutrition counseling for girls/women who currently have received little education on ways to improve the family and child dietary feeding practice is needed.
\end{abstract}

\section{Introduction}

Proper infant and young child feeding practice within the first two years of life is crucial for optimal child growth, development, better health, and preventing chronic degenerative disease [1]. According to the World Health Organization (WHO), introducing optimal complementary foods exactly at six months of age is vital to fulfilling children's nutritional requirements $[2,3]$.

Optimal complementary food is explained by fulfilling minimum dietary diversity, meal frequency, and an acceptable diet. Minimum dietary diversity refers to the proportion of children aged 6-23 months who received, on a preceding day, at least four or more varieties of foods from the seven standard food groups recommended by the WHO, without imposing a minimum intake restriction $[2,4-6]$.

Greater than two-thirds of malnutrition-related child deaths are associated with inadequate dietary feeding practices during the first two years of life. In developing countries, only a quarter of children met the required minimum dietary diversity $[7,8]$. Inappropriate child 
feeding practices contribute to poor physical growth, including irreversible outcomes of stunting, poor cognitive development, increased risk of infectious diseases, and mortality $[2,9,10]$.

Globally, there are efforts to improve the nutritional status of children by implementing different programs like the zero hunger draft [11], scaling up nutrition (SUN) movement [12-14], and sustainable development goals (SDGs) [15]. The World Health Assembly has a target for reducing stunted children by $40 \%$ in 2025 [9]. At least 12 of the 17 SDGs are highly related to nutrition $[16,17]$.

Currently, the Ethiopian government also set targets to improve the nutritional status of children through the National Nutrition Program (NNP-II) [18], Health Sector Transformation Plan (HSTP) [19], and Health Extension Program (HEP) [20]. Ethiopia also declared to end child malnutrition by 2030 [21, 22]. Despite the above efforts, currently, $38 \%$ of children are stunted, $10 \%$ are wasted, and $24 \%$ are underweight. In Ethiopia, $14 \%, 45 \%$, and $7 \%$ of children aged 6-23 months have met the minimum dietary diversity, minimum meal frequency, and minimum acceptable diet, respectively [23].

There are no documented studies on the dietary diversity feeding and associated factors among children aged 6-23 months in Northeast Ethiopia. Therefore, this study aimed to assess child dietary diversity score and associated factors among children aged 6-23 months in Golina district, Northeast Ethiopia.

\section{Methods and Materials}

2.1. Study Design, Setting, and Participants. A communitybased cross-sectional study was conducted in Golina district from February 15 to March 30, 2017. The district is found in the pastoralist region of Afar regional state, located $691 \mathrm{~km}$ northeast of Addis Ababa, the capital city of Ethiopia, and $220 \mathrm{~km}$ northwest of Samara, the capital city of the region. According to the projection of the 2007 census, the total population of the district was estimated to be 56,929; of which 5,727 were under-five children [24]. In the district, there were 1 general hospital, 2 health centers, and 10 health posts. Participants from the randomly selected kebeles were considered as the study population. Those who gave recently up-to-date information about their index children aged 6-23 months were the study unit.

2.2. Sample Size and Sampling Technique. The minimum sample size for each specific objective was separately calculated using a single population proportion formula (Table 1) and double population proportion formula using EPI Info 7.1 (Table 2).

Finally, the required size was taken as 347 , since this was found as the largest from all calculated sample sizes (Tables 1 and 2). Four kebeles were selected randomly from a total of eight kebeles in Golina district. The sample size was allocated proportionally for each selected kebele, based on the number of children less than two years of age. Then study units were selected using a simple random sampling method.
2.3. Data Collection Tools and Instruments. Data were collected using a semistructured questionnaire via face-to-face interviews with mothers of children aged 6-23 months. The questionnaire was prepared in English and translated into the local language and retranslated back to English to check the consistency. The Food and Agriculture Organization (FAO) meal frequency questionnaire was used to determine the weekly food group consumption of the children [2].

Pretesting was done on $10 \%$ of the calculated sample size in nonselected kebeles, and then the necessary modification was done. Anthropometric measurements, such as the mother's height and weight, were performed following WHO standard procedures. The mother's weight was measured using UNICEF electronic weighing scales. The weighing scales were calibrated and standardized using a $5 \mathrm{~kg}$ standard weight, every morning before the actual measurements. The children's age was determined using written official documents like vaccination cards. For those who had no written evidence of birthdate, a preprepared local calendar was used by cross-checking with the other family members. The children's vaccination status was assessed by card, BCG scar, and mother recalled.

Four data collectors and two supervisors, who were fluent in the local language, were employed. Two days of training, on the study tool and anthropometric measurement procedures, were given for data collectors and supervisors. When households found having two or more eligible children, one of them was selected randomly via the lottery method.

\subsection{Operational Definitions}

(i) Minimum child dietary diversity (MCDD): when a child gets at least 4 from the 7 WHO recommended food groups, regardless of the portion size and meal frequency [2].

(ii) Minimum meal frequency (MMF): calculated by grouping child age into two (6-8 months and 9-23 months). The acceptable MMF of children aged 6-8 months is considered as two or more times per 24 hours while for children aged 9-23 months it is three or more times [2].

(iii) Minimum acceptable diet (MAD): the percentage of breastfed children 6-23 months of age who had at least the minimum dietary diversity and the minimum meal frequency during the previous day, and nonbreastfed children 6-23 months of age who received at least two milk feedings and had at least the minimum dietary diversity not including milk feeds and the minimum meal frequency during the previous day [2].

2.5. Data Processing and Analysis. Data were edited, cleaned, coded, and entered into EPI Data 4.2 and exported to SPSS version 22 for analysis. Characteristics of study participants were summarized using descriptive statistics. Multivariable logistic regression was used to identify independent predictors of childhood dietary diversity. The strength of association was measured through the odds ratio at a $95 \%$ 
TABLE 1: Sample size calculation to assess the level of CDDS with the assumption of $95 \%$ CI, $5 \%$ margin of error, and $5 \%$ none response allowance.

\begin{tabular}{|c|c|c|}
\hline Percentage of minimum child dietary diversity score (\%) & Reference no. & Minimum final sample size \\
\hline 10.6 & [25] & 153 \\
\hline 68.4 & [26] & 347 \\
\hline 18.8 & [27] & 247 \\
\hline 12.6 & {$[28]$} & 177 \\
\hline 30.4 & [29] & 342 \\
\hline
\end{tabular}

TABLE 2: Sample size calculation to identify factors associated with CDDS using Epi Info (double population proportion formula).

\begin{tabular}{|c|c|c|c|c|c|c|c|}
\hline Variables & CI (\%) & $\begin{array}{c}\text { Power } \\
(\%)\end{array}$ & $\begin{array}{c}\text { Ratio (unexposed to } \\
\text { exposed) }\end{array}$ & $\begin{array}{c}\text { Outcome in the } \\
\text { unexposed group (\%) }\end{array}$ & $\begin{array}{l}\text { Outcome in the } \\
\text { exposed group (\%) }\end{array}$ & $\begin{array}{l}\text { No response } \\
\text { obtained }(\%)\end{array}$ & Sample size \\
\hline $\begin{array}{l}\text { Maternal } \\
\text { education [28] }\end{array}$ & 95 & 80 & 4.56 & 8.4 & 25.6 & 5 & 268 \\
\hline $\begin{array}{l}\text { Index child age } \\
{[28]}\end{array}$ & 95 & 80 & 1.15 & 6.8 & 18.3 & 5 & 307 \\
\hline
\end{tabular}

TABLE 3: Socioeconomic and demographic characteristics of study participants by the minimum dietary diversity score of children, in Golina district, Northeast Ethiopia, $2017(n=345)$.

\begin{tabular}{|c|c|c|c|c|c|}
\hline \multirow[t]{2}{*}{ Variable } & \multirow[t]{2}{*}{ Category } & \multirow[t]{2}{*}{ Total, $n(\%)$} & \multicolumn{2}{|c|}{$\begin{array}{l}\text { Minimum child dietary diversity } \\
\text { score (MCDDS) }\end{array}$} & \multirow[t]{2}{*}{$P$ value } \\
\hline & & & Meet, $n(\%)$ & Not meet, $n(\%)$ & \\
\hline Maternal religion & $\begin{array}{l}\text { Muslim } \\
\text { Others* }\end{array}$ & $\begin{array}{c}315(91.3) \\
30(8.7)\end{array}$ & $\begin{array}{c}106(87.6) \\
15(12.4)\end{array}$ & $\begin{aligned} 209 & (93.3) \\
15 & (6.7)\end{aligned}$ & 0.073 \\
\hline Maternal ethnicity & $\begin{array}{c}\text { Afar } \\
\text { Others** }\end{array}$ & $\begin{array}{l}284(82.3) \\
61(17.7)\end{array}$ & $\begin{array}{l}92(76) \\
26(24)\end{array}$ & $\begin{array}{c}192(85.7) \\
32(14.3)\end{array}$ & 0.024 \\
\hline Maternal age & $\begin{array}{c}15-24 \\
25-34 \\
\geq 35 \\
\end{array}$ & $\begin{array}{c}95(27.5) \\
195(56.5) \\
55(16) \\
\end{array}$ & $\begin{array}{ll}39 & (32.2) \\
65 & (53.7) \\
17 & (14.1) \\
\end{array}$ & $\begin{array}{c}56(25.0) \\
130(58.0) \\
38(17.0) \\
\end{array}$ & 0.338 \\
\hline Maternal education status & $\begin{array}{c}\text { No formal education } \\
\text { Primary } \\
\text { Secondary and above }\end{array}$ & $\begin{array}{c}254(73.6) \\
35(10.1) \\
56(16.3) \\
\end{array}$ & $\begin{array}{ll}74 & (62.2) \\
16 & (13.2) \\
31 & (25.6) \\
\end{array}$ & $\begin{aligned} & 180(80.4) \\
& 19(8.5) \\
& 25(11.1) \\
&\end{aligned}$ & $<0.0001$ \\
\hline Maternal occupation & $\begin{array}{c}\text { Government employee } \\
\text { Pastoralist } \\
\text { Housewife } \\
\text { Others*** }\end{array}$ & $\begin{array}{c}41(11.9) \\
216(62.6) \\
62(18) \\
26(7.5) \\
\end{array}$ & $\begin{array}{l}24(19.8) \\
65(53.7) \\
17(14.0) \\
15(12.3) \\
\end{array}$ & $\begin{array}{c}17(7.6) \\
151(67.4) \\
45(20.1) \\
11(4.9) \\
\end{array}$ & $<0.0001$ \\
\hline Maternal residence & $\begin{array}{l}\text { Urban } \\
\text { Rural }\end{array}$ & $\begin{array}{c}81(23.5) \\
264(76.5) \\
\end{array}$ & $\begin{array}{c}52(23.2) \\
172(76.8) \\
\end{array}$ & $\begin{array}{l}29(24) \\
92(76)\end{array}$ & 0.875 \\
\hline Index child sex & $\begin{array}{l}\text { Male } \\
\text { Female }\end{array}$ & $\begin{array}{l}165(47.8) \\
180(52.2)\end{array}$ & $\begin{array}{l}48(39.7) \\
73(60.3)\end{array}$ & $\begin{array}{l}117(52.2) \\
107(47.8)\end{array}$ & 0.026 \\
\hline Index child age & $\begin{array}{l}\text { 6-8 months } \\
9-11 \text { months } \\
12-23 \text { months }\end{array}$ & $\begin{array}{c}53(15.4) \\
77(22.3) \\
215(62.3)\end{array}$ & $\begin{array}{l}26(21.5) \\
20(16.5) \\
75(62.0)\end{array}$ & $\begin{array}{c}27(12.1) \\
57(25.4) \\
140(62.5)\end{array}$ & 0.025 \\
\hline $\begin{array}{r}\text { Maternal age (it } \\
\text { Fam } \\
\text { Index child age }(i\end{array}$ & $\begin{array}{l}\text { pleted years) } \\
\text { apleted month) }\end{array}$ & $\begin{array}{l}\mathrm{M} \\
\mathrm{M} \\
\mathrm{M}\end{array}$ & $\begin{array}{l}\text { SD } \\
\text { SD } \\
\text { SD }\end{array}$ & $\begin{array}{c}27.97 \pm 5.43 \\
5.81 \pm 2.13 \\
13.76 \pm 4.57\end{array}$ & \\
\hline
\end{tabular}

${ }^{*}$ Orthodox, Protestant, and Catholic. ${ }^{* *}$ Amhara and Oromo. ${ }^{* * *}$ Student, merchant, and daily laborer.

confidence interval. Predictor variables with the $P$ value $<0.25$ at bivariable analysis were included in the multivariable logistic regression model and analyzed using the backward logistic regression model. Statistical significance was declared at a $P$ value $<0.05$.

Multicollinearity was checked using standard error as a cutoff of 2, but no variables were found. The percentage of the model accurately classified was $70.7 \%$, with Hosmer and
Lemeshow goodness-of-fit test $P$ value $=0.857$, indicating the model fits well.

\section{Result}

3.1. Sociodemographic Characteristics of Study Participants. A total of 345 study participants were included, with a $97 \%$ response rate. Nearly 264 (76.5\%) were lived in rural areas, 
TABLE 4: Maternal healthcare and nutritional status characteristics by the minimum dietary diversity score of children, in Golina district, Northeast Ethiopia, $2017(n=345)$.

\begin{tabular}{|c|c|c|c|c|c|}
\hline \multirow{2}{*}{ Variables } & \multirow{2}{*}{ Category } & \multirow{2}{*}{ Total, $n(\%)$} & \multicolumn{2}{|c|}{ MCDDS } & \multirow{2}{*}{$P$ value } \\
\hline & & & Meet, $n(\%)$ & Not meet, $n(\%)$ & \\
\hline \multirow{2}{*}{ Maternal ANC follow-up* } & Yes & $143(41.5)$ & $43(35.5)$ & $100(44.6)$ & \multirow{2}{*}{0.101} \\
\hline & No & $202(58.5)$ & $78(64.5)$ & $124(55.4)$ & \\
\hline \multirow{2}{*}{ Birth place } & Home & $267(76.8)$ & $93(76.9)$ & $174(77.7)$ & \multirow{2}{*}{0.862} \\
\hline & Health institution & $78(23.2)$ & $28(23.1)$ & $50(22.3)$ & \\
\hline \multirow{2}{*}{ Nutrition counseling and health education** } & Yes & $82(23.8)$ & $34(28.1)$ & $48(21.4)$ & \multirow{2}{*}{0.165} \\
\hline & No & $263(76.2)$ & $87(71.9)$ & $176(78.6)$ & \\
\hline \multirow{3}{*}{ Maternal BMI $\left(\mathrm{kg} / \mathrm{m}^{2}\right)$} & $<18.5$ & $73(21.2)$ & $19(15.7)$ & $54(24.1)$ & \multirow{3}{*}{0.012} \\
\hline & $18.5-24.9$ & $32(9.3)$ & $6(5.0)$ & $26(11.6)$ & \\
\hline & $\geq 25$ & $240(69.5)$ & $96(79.3)$ & $144(64.3)$ & \\
\hline
\end{tabular}

${ }^{*}$ Mother of the index child making ANC follow-up at least once. ${ }^{* *}$ Getting counseling and education regarding maternal feeding practice (during pregnancy and lactation) and on child feeding practice.

TABLE 5: Child healthcare and feeding-related characteristics by the minimum dietary diversity score of children, in Golina district, Northeast Ethiopia $(n=345)$.

\begin{tabular}{|c|c|c|c|c|c|}
\hline \multirow{2}{*}{ Variables } & \multirow{2}{*}{ Category } & \multirow{2}{*}{ Total, $n(\%)$} & \multicolumn{2}{|c|}{ MCDDS } & \multirow{2}{*}{$P$ value } \\
\hline & & & Meet, $n(\%)$ & Not meet, $n(\%)$ & \\
\hline \multirow{2}{*}{ Exclusive breastfeeding for the first six months } & Yes & $115(33.3)$ & $50(41.3)$ & $65(29)$ & \multirow{2}{*}{0.021} \\
\hline & No & $230(66.7)$ & $71(58.7)$ & $159(71)$ & \\
\hline \multirow{2}{*}{ Food taboo for children* } & Yes & $14(4.1)$ & $2(1.7)$ & $12(5.4)$ & \multirow{2}{*}{0.096} \\
\hline & No & $331(95.9)$ & $119(98.3)$ & $212(94.6)$ & \\
\hline \multirow{2}{*}{ Minimum meal frequency (MMF) } & Meet & $185(53.6)$ & $67(55.4)$ & $118(52.7)$ & \multirow{2}{*}{0.632} \\
\hline & Not meet & $160(46.4)$ & $54(44.6)$ & $106(47.3)$ & \\
\hline \multirow{2}{*}{ Minimum acceptable diet (MAD) } & Meet & $67(19.4)$ & $67(55.4)$ & $0(0)$ & \multirow{2}{*}{$<0.0001$} \\
\hline & Not meet & $278(80.6)$ & $54(44.6)$ & $224(100)$ & \\
\hline \multirow{2}{*}{ Immunization status of the child (at least one type) } & Yes & $170(49.3)$ & $62(51.3)$ & $108(48.2)$ & \multirow{2}{*}{0.592} \\
\hline & No & $175(50.7)$ & $59(47.7)$ & $116(51.8)$ & \\
\hline \multirow{3}{*}{ Birth order of the child** } & $\leq 3$ & $174(50.4)$ & $71(58.7)$ & $103(46)$ & \multirow{3}{*}{0.047} \\
\hline & $4-5$ & $93(22.6)$ & $24(19.8)$ & $69(30.8)$ & \\
\hline & $\geq 6$ & $78(27)$ & $26(21.5)$ & $52(23.2)$ & \\
\hline
\end{tabular}

*Any type of food which is strictly prohibited for children either culturally or religiously. ${ }^{* *}$ The order of the index childbirth from all successive births.

and $284(82.3 \%)$ were of Afar ethnicity. Almost quarters (254 $(73.6 \%))$ of mothers had not attended formal education. More than half $(180(52.2 \%))$ of children were female (Table 3).

\subsection{Maternal Health and Nutritional Status Characteristics.} More than half $(202(58.5 \%))$ of mothers were not attended ANC, and 267 (76.8\%) of them were given birth at home (Table 4).

3.3. Child Healthcare and Feeding Practice. Nearly twothirds $(115(33.3 \%))$ of children were not exclusively breastfed for the first six months of age. About 67 (19.4\%) of children have met the minimum acceptable diet (Table 5).

3.4. Percentage of Weekly Food Groups' Consumption. All of the children consumed cereals for one week before the survey. But only $35.9 \%$ of them consumed flesh foods.
Children meeting the dietary diversity score was $35.1 \%$ (Figure 1).

3.5. Infant and Young Child Feeding Practice. Among all children, only $19.4 \%$ of them met the minimum acceptable diet (Figure 2).

3.6. Factors Associated with Minimum Child Dietary Diversity Score of Children. Child dietary diversity score had no significant association with place of delivery, birth order, maternal residence, child immunization status, and food taboo (Table 6). Children whose mothers attended formal education were 3.042 times $(\mathrm{AOR}=3.042(1.312-7.052))$ more likely to meet the minimum optimal dietary diversity score than children whose mothers not attended secondary and above educational status. Children whose mothers were underweight and/or overweight were $51.2 \%(\mathrm{AOR}=0.488,95 \% \mathrm{CI},(0.259-0.918))$ and $68.10 \%$ $(\mathrm{AOR}=0.319,95 \% \mathrm{CI},(0.119-0.855))$ less likely to meet the optimum minimum dietary diversity score than children whose mothers were with normal BMI, respectively. 


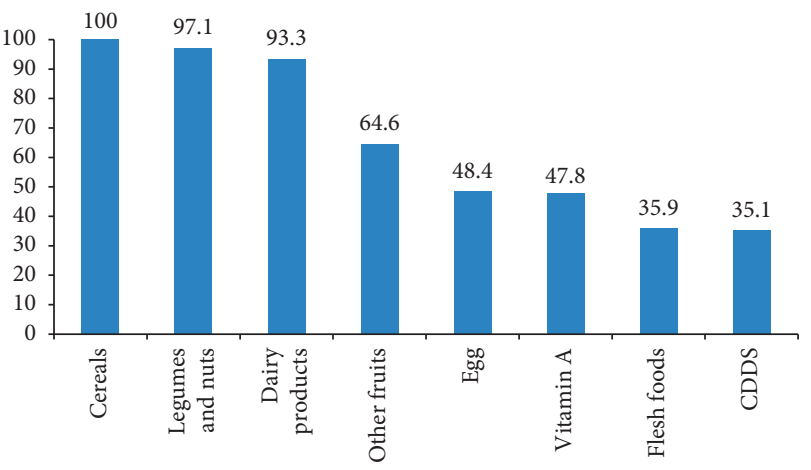

Figure 1: Percentage of children, who consumed the seven food groups one week before the survey, in Golina district, Northeast Ethiopia, 2017.

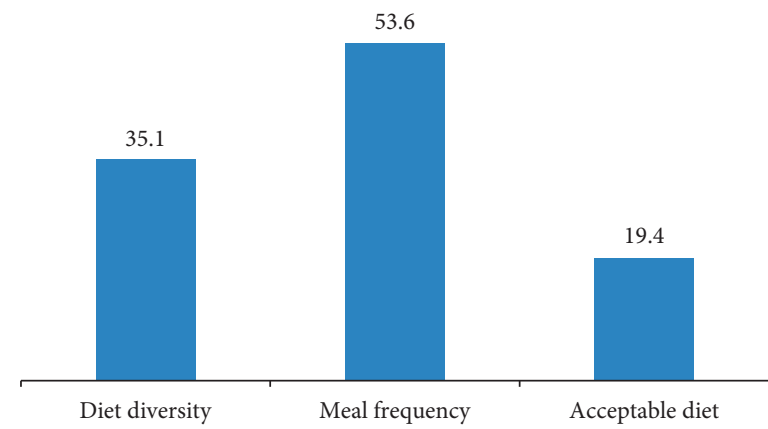

Figure 2: Percentage of infant and young child feeding practice among children aged 6-23 months in Golina district, Northeast Ethiopia ( $n=345)$.

TABle 6: Factors associated with child dietary diversity score in Northeast Ethiopia $(n=345)$.

\begin{tabular}{lcccc}
\hline \multirow{2}{*}{ Variables/Category } & \multicolumn{2}{c}{ Minimum CDDS } & COR $(95 \%$ CI $)$ & AOR (95\% CI) \\
\hline Maternal education status & Meet $(\geq 4)$ & Not Meet $(\leq 3)$ & 1 & 1 \\
No formal education & $74(61.16)$ & $180(80.36)$ & $2.048(0.999-4.200)$ & $1.877(0.807-4.370)$ \\
Attended primary & $16(13.22)$ & $19(8.48)$ & $3.016(1.668-5.454)$ & $3.042(1.312-7.052)$ \\
Secondary and above & $31(25.62)$ & $25(11.16)$ & 1 & 1 \\
\hline Maternal BMI in $\left(\mathrm{kg} / \mathrm{m}^{2}\right)$ status & & & & \\
Normal & $19(15.7)$ & $54(24.11)$ & $0.528(0.295-0.946)$ & $0.488(0.259-0.918)$ \\
Underweight & $6(4.96)$ & $26(11.61)$ & $0.346(0.137-0.873)$ & $0.319(0.119-0.855)$ \\
Overweight & $96(79.34)$ & $144(64.28)$ &
\end{tabular}

The variables entered into the model was maternal educational status, maternal marital status, maternal BMI status, number of under-five children at the household, nutrition counseling during antenatal care follow-up, household decision making power, livestock, index child sex, maternal ethnicity, family size, maternal age, child age, and religion.

\section{Discussion}

In this study, children who met the minimum dietary diversity score were $35.1 \%$, (95\% CI: $(30 \%-40 \%)$ ). This figure is higher than that reported in studies done in Ethiopia such as Arsi Negele district (18.8\%) [27], Gorche district (10.6\%) [25], and Dangila town (12.6\%) [28]. It is also higher than that reported in African countries such as Tanzania (32.58\%) and Uganda (29.5\%) [30]. But it was lower than those reported in other studies done in Ghana (51.4\%) [31], China (63.2\%) [32], Indonesia (68.4\%) [26], and Kenya (39.06\%) [30]. The reason might be due to the difference in the data collection time, awareness creation by health policy systems, media exposure, and community child feeding practice.
This study revealed that maternal nutritional status (BMI) was associated with meeting the minimum dietary diversity score of children. This finding could be explained by the good nutritional status of the mother which might be due to her improved feeding practice, which could be a proxy for her child's good feeding practice. This might be also influenced by decision making and media exposure [28]. This might be also due to wealth index, place of delivery, maternal age, and maternal employment [30].

Maternal education was found to be associated with meeting the child's minimum dietary diversity score. This is in line with studies done in Ethiopia such as Dangilla [28] and African countries (Nigeria [33], Kenya, Uganda, and Tanzania [30]), and Asian country, Nepal [34]. This might be explained by the fact that as the mother's educational level 
increases, her knowledge, attitude, and practice towards dietary feeding practice might be improved. Also, in addition, as the mother's educational level increases, she might have antenatal care follow-up and media exposure, by which she could get nutritional counseling and improve her child feeding practice $[28,30]$.

In conclusion, maternal nutrition status and maternal education status were associated with child dietary diversity scores. This study revealed that children who met the minimum dietary diversity score were few. Therefore, increased emphasis on the importance of the education of girls (future mothers) and nutrition counseling for girls/women who received little education on ways to improve the family and child dietary feeding practice is needed.

$\begin{array}{ll}\text { Abbreviations } \\ \text { AOR: } & \text { Adjusted odds ratio } \\ \text { BCG: } & \text { Bacillus Calmette-Guerin } \\ \text { BMI: } & \text { Body mass index } \\ \text { CI: } & \text { Confidence interval } \\ \text { CDDS: } & \text { Child dietary diversity score } \\ \text { EDHS: } & \text { Ethiopian Demographic and Health Survey } \\ \text { FAO: } & \text { Food and Agriculture Organization } \\ \text { MDDS: } & \text { Minimum dietary diversity score } \\ \text { MMF: } & \text { Minimum meal frequency } \\ \text { MUAC: } & \text { Mid-upper arm circumference } \\ \text { SPSS: } & \text { Statistical Package for Social Science } \\ \text { UNICEF: } & \text { United Nations Children's Fund } \\ \text { WHO: } & \text { World Health Organization. }\end{array}$

\section{Data Availability}

The datasets analyzed during the current study are available from the corresponding author upon reasonable request.

\section{Ethical Approval}

Ethical approval was obtained from the Institutional Review Board of the College of Health Sciences, Mekelle University (protocol approval: ERC-0936/2007). An official letter of support was obtained from Afar Regional Health Bureau, Golina district Health and Administrative Offices. The study objective was explained to parents. Privacy and confidentiality were ensured at all levels. Interview and anthropometric measurements were conducted in a private area and their name was not requested and recorded.

\section{Consent}

Informed written consent was obtained from study participants. Counseling and linkage to appropriate healthcare and support were given.

\section{Conflicts of Interest}

The authors declare that they have no conflicts of interest.

\section{Authors' Contributions}

GFM conceived and designed the study, performed analysis, interpreted the data, and drafted the manuscript. FWF and SA were involved in the analysis and interpretation of the data and critically reviewed the manuscript. All authors read and approved the final manuscript.

\section{Acknowledgments}

The authors would like to express their deepest gratitude to Samara University for facilitating this study. Our appreciation also goes to supervisors, data collectors, and study participants.

\section{References}

[1] World Health Organization, Global Strategy for Infant and Young Child Feeding, World Health Organization, Geneva, Switzerland, 2003.

[2] World Health Organization, Indicators for Assessing Infant and Young Child Feeding Practices: Part 1: Definitions: Conclusions of a Consensus Meeting Held 6-8 November 2007, World Health Organization, Washington, DC, USA, 2008.

[3] World Health Organization, Indicators for Assessing Infant and Young Child Feeding Practices: Part 2: Measurement, World Health Organization, Geneva, Switzerland, 2010.

[4] G. L. Kennedy, Evaluation of Dietary Diversity Scores for Assessment of Micronutrient Intake and Food Security in Developing Countries, Wageningen University, Wageningen, Netherlands, 2009.

[5] CARE, Young Child Feeding Practices: Collecting and Using Data: A Step-by-Step Guide: Cooperative for Assistance and Relief Everywhere, Inc[CARE], Waltham, MA, USA, 2010.

[6] N. Steyn, J. Nel, G. Nantel, G. Kennedy, and D. Labadarios, "Food variety and dietary diversity scores in children: are they good indicators of dietary adequacy?" Public Health Nutrition, vol. 9, no. 5, pp. 644-650, 2006.

[7] C. G. Victora, L. Adair, C. Fall et al., "Maternal and child undernutrition: consequences for adult health and human capital," The Lancet, vol. 371, no. 9609, pp. 340-357, 2008.

[8] R. E. Black, L. H. Allen, Z. A. Bhutta et al., "Maternal and child undernutrition: global and regional exposures and health consequences," The Lancet, vol. 371, no. 9608, pp. 243-260, 2008.

[9] World Health Organization, Global Nutrition Targets 2025: Stunting Policy Brief, World Health Organization, Geneva, Switzerland, 2014.

[10] L. H. Allen and S. R. Gillespie, What Works? A Review of the Efficacy and Effectiveness of Nutrition Interventions, Asian Development Bank, Mandaluyong, Philippines, 2001.

[11] K. Von Grebmer, J. Bernstein, D. Nabarro et al., Global Hunger Index: Getting to Zero Hunger, International Food Policy Research Institute, Washington, DC, USA, 2016.

[12] S. Horton, M. Shekar, and M. Ajay, Scaling up Nutrition: What Will it Cost?, The World Bank, Washington, DC, USA, 2009.

[13] World Health Organization, "Accelerating nutrition improvements (ani): mapping of stakeholders and nutrition actions," in Three Scaling-Up Countries in Sub-saharan Africa: Report of a Meeting, pp. 27-28, World Health Organization, Addis Ababa, Ethiopia, 2014.

[14] R. Shrimpton, L. M. du Plessis, H. Delisle et al., "Public health nutrition capacity: assuring the quality of workforce 
preparation for scaling up nutrition programmes," Public Health Nutrition, vol. 19, no. 11, pp. 2090-2100, 2016.

[15] K. W. Robert, T. M. Parris, and A. A. Leiserowitz, "What is sustainable development? Goals, indicators, values, and practice," Environment: Science and Policy for Sustainable Development, vol. 47, no. 3, pp. 8-21, 2005.

[16] S. S. Lim, K. Allen, Z. A. Bhutta et al., "Measuring the healthrelated sustainable development goals in 188 countries: a baseline analysis from the global burden of disease study 2015," The Lancet, vol. 388, no. 10053, pp. 1813-1850, 2016.

[17] D. Griggs, M. Stafford-Smith, O. Gaffney et al., "Sustainable development goals for people and planet," Nature, vol. 495, no. 7441, pp. 305-307, 2013.

[18] Central Statistical Agency, National Nutrition Program 2016-2020, Federal Democratic Republic of Ethiopia, Ethiopia, 2015.

[19] Federal Democratic Republic of Ethiopia, Ministry of Health. Health Sector Transformation Plan (2015/16-2019/20), Federal Democratic Republic of Ethiopia, Ethiopia, 2015.

[20] H. Wang, R. Tesfaye, G. NV Ramana, and C. T. Chekagn, Ethiopia Health Extension Program: An Institutionalized Community Approach for Universal Health Coverage, The World Bank, Washington, DC, USA, 2016.

[21] Ethiopian Public Health Institute, An Evidence Informed Policy Brief; Reducing Stunting in Ethiopia: "From Promise to Impact", Ethiopian Public Health Institute, Addis Ababa, Ethiopia, 2019.

[22] Ethiopian Ministory of Health, Seqota Declaration Implementation Plan (2016-2030): Summary Program Approach Document, Ethiopian Ministory of Health, Ethiopia, 2016.

[23] Central Statistical Agency, Ethiopian Demographic and Health Survey, Federal Democratic Republic of Ethiopia, Ethiopia, 2016.

[24] Federal Democratic Republic of Ethiopia, Population Census Commission. Summary and Statistical Report of the 2007 Population and Housing Census, Central Statistics Agency, Addis Ababa, Ethiopia, 2008.

[25] D. Dangura and S. Gebremedhin, "Dietary diversity and associated factors among children 6-23 months of age in Gorche district, Southern Ethiopia: cross-sectional study," BMC Pediatrics, vol. 17, no. 1, p. 6, 2017.

[26] C. S. Ng, M. J. Dibley, and K. E. Agho, "Complementary feeding indicators and determinants of poor feeding practices in Indonesia: a secondary analysis of 2007 demographic and health survey data," Public Health Nutrition, vol. 15, no. 5, pp. 827-839, 2012.

[27] T. Kassa, B. Meshesha, Y. Haji, and J. Ebrahim, “Appropriate complementary feeding practices and associated factors among mothers of children age 6-23 months in Southern Ethiopia," BMC Pediatrics, vol. 16, no. 1, p. 31, 2016.

[28] M. Beyene, A. G. Worku, and M. M. Wassie, "Dietary diversity, meal frequency and associated factors among infant and young children in Northwest Ethiopia: a cross- sectional study," BMC Public Health, vol. 15, no. 1, p. 1007, 2015.

[29] V. Khanal, K. Sauer, and Y. Zhao, "Determinants of complementary feeding practices among Nepalese children aged 6-23 months: findings from Demographic and Health Survey 2011," BMC Pediatrics, vol. 13, no. 1, p. 31, 2013.

[30] C. A. Gewa and T. F. Leslie, "Distribution and determinants of young child feeding practices in the East African region: demographic health survey data analysis from 2008-2011," Journal of Health, Population, and Nutrition, vol. 34, no. 1, p. 6, 2015.
[31] A. I. Issaka, K. E. Agho, P. Burns, A. Page, and M. J. Dibley, "Determinants of inadequate complementary feeding practices among children aged 6-23 months in Ghana," Public Health Nutrition, vol. 18, no. 4, pp. 669-678, 2015.

[32] D. B. Hipgrave, X. Fu, H. Zhou et al., "Poor complementary feeding practices and high anaemia prevalence among infants and young children in rural central and western China," European Journal of Clinical Nutrition, vol. 68, no. 8, pp. 916-924, 2014.

[33] F. A. Ogbo, P. Ogeleka, and A. O. Awosemo, "Trends and determinants of complementary feeding practices in Tanzania, 2004-2016," Tropical Medicine and Health, vol. 46, p. 40, 2018.

[34] K. P. Gautam, M. Adhikari, R. B. Khatri, and M. D. Devkota, "Determinants of infant and young child feeding practices in Rupandehi, Nepal," BMC Research Notes, vol. 9, no. 1, p. 35, 2016. 